\title{
Improved Calculation Methodology for Cycle Harvesting of Milled Peat
}

\author{
Victoria Sizova ${ }^{1}$, and Elena Chertkova $^{1}$ \\ ${ }^{1}$ Tver State Technical University, 22 Af. Nikitin Street, 170026, Tver, Russia
}

\begin{abstract}
The article presents the calculation methods for cycle harvesting of milled peat. They are recommended for the three flow sheets of milled peat production: (a) a method based on a mechanical extraction by means of tanker harvesters; (b) a separate method of peat harvesting and transporting to large stacks and (c) a method based on pneumatic peat harvesting. Positive and negative aspects of the given methods are described and the improved calculation methods for cycle harvesting of milled peat are offered. The proposed methods take into account the weather conditions of a peat production region, the decrease in the initial moisture in the second and subsequent cycles after precipitation, due to the loss of fragmented peat from the previous cycle. A drying rate reduction factor is introduced into calculations in view of the uneven spread of milled crumbs. The performed calculations show that the reduced to $15 \%$ cycle harvests are possible to use in a design in comparison with those calculated by the previous technical design standards.
\end{abstract}

\section{Introduction}

Design and research organizations have developed two methods for calculating cycle harvesting, namely, the method of the former Moscow Peat Institute and the method of the All-Russian Research Institute of Peat Industry.

It is proposed that the correction factors should be introduced into the current formula for calculation of milled peat cycle harvesting to take into account the losses of the finished products from a previous cycle, the influence of an uneven peat crumb layer on a drying rate, as well as various potentials for natural drying in the peat production regions.

Correction factors are determined by the All-Russian Research Institute of Peat Industry recommendation on the calculation of cycle harvesting. They are recommended for the three flow sheets of milled peat production: (a) a method based on a mechanical extraction by means of tanker harvesters; (b) a separate method of peat harvesting and transporting to large stacks and (c) a method based on pneumatic peat harvesting [1-2].

According to the Moscow Peat Institute technique developed in the late 30s and early 40 s of the XXth century, cycle harvests are calculated by formula (1): 


$$
q_{\mathrm{c}}=\frac{10 h_{\mathrm{m}} \gamma_{\mathrm{o}}\left(100-w_{\mathrm{o}}\right)}{100-w_{\mathrm{con}}} \alpha_{\mathrm{c}}
$$

where: 10 - conversion factor from $\mathrm{kg} / \mathrm{m}^{2}$ to $\mathrm{t} / \mathrm{ha}$;

$h_{\mathrm{m}}$ - average (normative) milling depth, $\mathrm{m}$;

$\gamma_{\mathrm{o}}$ - density of the unconsolidated peat deposit, $\mathrm{kg} / \mathrm{m}^{3}$;

$w_{\mathrm{o}}$ - operational moisture of the peat deposit upper layer, \%;

$\alpha_{c}$ - cycle harvesting factor;

$w_{\text {con }}$ - conditional moisture of the finished product, $\%$.

Conditional moisture is set to $40 \%$ for harvesting peat to produce fuel and briquettes, as well as for supplying feedstock to the production of heat-insulating and bedding material, and to $55 \%$ for further production of various types of fertilizers [3-6]. The advantage of this formula is the simplicity of calculations, although it has several significant drawbacks. The standard milling depth of a peat deposit is calculated on assumption that moisture from a peat crumb layer evaporates $2.4 \mathrm{~kg} / \mathrm{m}^{2}$ per day on average, regardless of the peat production geographical area. However, the follow-up study conducted by the All-Russian Research Institute of Peat Industry found that there are critical differences $( \pm 20 \%)$ in potential days of drying peat between different regions.

In course of milling operations of the second and subsequent cycles after precipitation, a layer of milled crumbs is formed from the newly milled peat bed and residues (losses) of dried peat from the previous cycle, which reduce the initial moisture and improve cycle harvesting. However, this factor is not taken into account in formula. According to the research carried out by the All-Russian Research Institute of Peat Industry, the full range of meteorological factors affecting peat drying is advisable to replace by one parameter - the amount of moisture evaporated from the water-saturated surface of the N.M. Topolnitsky soil evaporator.

When calculating a normative milling depth in formula (1), we take the evaporation discharge from a peat layer as a main indicator of day type in terms of a drying rate. Moisture evaporation from the peat layer depends on daily mean temperature, relative air moisture in day-time, 3 p.m. cloud cover and amount of precipitation - all this complicates greatly the calculations. The formula is valid provided that the average replication of tedding in a technological cycle is 2.75 [7-8]. According to investigations conducted by the All-Russian Research Institute of Peat Industry, a drying rate decreases because of uneven spread of milled crumbs, but this factor is not taken into account in formula (1).

According to the above-mentioned Institute methodology, cycle harvesting ( $t / \mathrm{ha}$ ) is recommended to calculate by formulas:

$$
\begin{gathered}
q_{\mathrm{c}}=10 P_{\mathrm{d}}\left(1+W_{\mathrm{con}}\right) \alpha_{\mathrm{c}} \\
P_{\mathrm{d}}=\left(\frac{i_{\mathrm{e}} \tau_{\mathrm{c}}}{\mathrm{M} K_{\mathrm{h}}}\right)^{0.75}\left(\gamma_{\mathrm{b} . \mathrm{dr}} d_{\mathrm{av}}\right)^{0.25}
\end{gathered}
$$

where: 10 - conversion factor from $\mathrm{kg} / \mathrm{m}^{2}$ to $\mathrm{t} / \mathrm{ha}$;

$P_{\mathrm{d}}-$ specific loading of fragmented peat after milling on absolutely dry basis, $\mathrm{kg} / \mathrm{m}^{2}$;

$W_{\text {con }}$ - conditional moisture content, $\mathrm{kg} / \mathrm{kg}$;

$\alpha_{c}-$ cycle harvesting factor;

$i_{\mathrm{e}}$ - long-term average annual effective evaporation from the soil evaporator surface per day, $\mathrm{kg} / \mathrm{m}^{2}$;

$\tau_{\mathrm{c}}-$ scheduled cycle duration, days; 
M - coefficient taking into account the deposit type and the peat decay degree, the equilibrium, initial and final moisture content, the number of turnings and the time of their completion, as well as peat crumb moistening when tedding;

$K_{\mathrm{h}}$ - reduction factor of peat drying rate due to uneven spread of fragmented peat;

$\gamma_{\text {b.dr }}$ - bulk density of a milled peat layer on absolutely dry basis $\mathrm{kg} / \mathrm{m}^{3}$;

$d_{\mathrm{av}}-$ weighted average particle size of milled peat, $\mathrm{m}$.

The calculations of cycle harvesting by formulas ( 2 and 3$)$ let us take into account complex effect of meteorological, technological and organizational factors on peat drying. However, this technique was not introduced into technological design standards for milled peat cycle harvesting calculation by the following main reasons:

- the relatively laborious method of calculating the coefficient $\mathrm{M}$ for some drying periods between technological operations;

- in formula (3) the coefficient that takes into account the drying rate decrease due to uneven spread is recommended to have a fairly wide range (from 1.10 to 1.25), which underrates the performance expectations of cycle harvesting;

- calculations by formulas (2 and 3) provide for the transition from the concept of peat moisture to moisture content, which is perceived negatively by peat production personnel.

\section{Review}

Currently, in the process of designing technological and production indicators of milled peat extraction, there is a need to improve the methods of milled peat cycle harvesting calculation. This is stipulated by stringent market relations, with regular supply of peat products to a consumer in the contracted volumes being of paramount importance. The calculation of cycle harvesting based on mechanical peat extraction stems from the Moscow Peat Institute method, but is expanded by some modifications. It is necessary to introduce a correction for the decrease in initial moisture content in the second and subsequent cycles after precipitation due to peat crumb losses from the previous cycle. When calculating the initial moisture content in the second and subsequent cycles after precipitation, methodologists of the All-Russian Research Institute of Peat Industry provide for the use of an overall cycle harvesting factor, whereas the authors of the article consider that it is necessary to exclude from the calculation the amount of peat crumb pressed into a peat deposit by peat machine movers. In addition, proper allowance must be made for the potentials of peat drying in a particular peat production geographical area. The reduction factor of peat drying rate due to uneven spread of fragmented peat should be introduced into calculations [9].

In the design of peat deposit development by the milled method of peat production based on mechanical extraction, cycle harvesting must be calculated by the refined formula (4):

$$
q_{\mathrm{c} . \mathrm{av}}=\left(\mathrm{a}_{1} q_{\mathrm{c.d}}+\mathrm{a}_{2} q_{\mathrm{c} . \mathrm{dr}}\right) K_{i} / K_{\mathrm{h}}
$$

where: $q_{\text {c.av }}-$ weighted average of cycle harvesting, $\mathrm{t} /$ ha;

$\mathrm{a}_{1}, \mathrm{a}_{2}-$ the proportion of cycles in a post-precipitation season and when performing the second and subsequent cycles after precipitation (according to the All-Russian Research Institute of Peat Industry $\mathrm{a}_{1}=0.4 ; \mathrm{a}_{2}=0.6$ );

$q_{\text {c.d }}$ - cycle harvesting of milled peat that makes allowance for operational normative moisture content of the peat deposit upper layer $\mathrm{t} / \mathrm{ha}$;

$q_{\text {c.dr. }}$ - cycle harvesting of milled peat that makes allowance for initial moisture content with due consideration of dried peat residues from the previous cycle, $t$ / ha; 
$K_{i-}$ coefficient that takes into account the potentials of drying days of a particular region in comparison with average weather conditions the standard milling depth is based on;

$K_{\mathrm{h}}-$ coefficient that takes into account the decrease in drying rate of milled crumbs due to uneven spread.

Cycle harvesting of milled peat in the first cycle after precipitation are calculated by formula (1) that was factored in the norms of technological design. However, the cycle harvesting factor is taken according to the specified data of the All-Russian Research Institute of Peat Industry. As for the second and subsequent cycles after precipitation, peat harvesting is also calculated by formula (1), with the initial moisture content being determined in accordance with the above-mentioned Institute method by formula (5):

$$
W_{\text {o.dr }}=\left(W_{\text {o.d }}-W_{\mathrm{hv}}\right)\left(1-\sum L_{i} / 100\right)+W_{\mathrm{av}}
$$

where: $W_{\text {o.dr. }}$ - operational (initial) moisture content of the peat crumb layer after milling together with dried peat residues from the previous cycle, $\mathrm{kg} / \mathrm{kg}$;

$W_{\text {o.d }}$ - operational moisture content of the peat deposit upper layer, $\mathrm{kg} / \mathrm{kg}$;

$W_{\mathrm{hv}}-$ moisture content of the harvested milled peat, $\mathrm{kg} / \mathrm{kg}$;

$\Sigma L_{i}-$ total losses of milled peat in swathing and harvesting, \%;

$W_{\text {av }}$ - average moisture content over the whole layer of milled peat in harvesting, $\mathrm{kg} / \mathrm{kg}$.

Moisture content, i.e. the ratio of water mass to dry weight in peat is determined by formula (6):

$$
W=\frac{w}{100-w}
$$

where: $w$ - relative moisture of peat, $\%$.

To calculate the relative moisture of peat by water content, we use the following formula (7):

$$
w=\frac{100 W}{1+W}
$$

Moisture basis is taken as $45 \%$ for harvesting peat to produce fuel, briquettes and bedding material (conventional moisture $40 \%$ ), and if conventional moisture is $55 \%$, harvesting moisture is $60 \%$ [10].

Losses of milled peat in swathing and harvesting are approximately $10-15 \%$ per operation. It is recommended that such losses should be observed experimentally on the factory floor.

Average moisture content over the whole layer of milled peat in harvesting based on mechanical extraction is taken equal to the designed moisture content of the harvested milled peat, i.e. $W_{\mathrm{av}}=W_{\mathrm{hv}}, \mathrm{kg} / \mathrm{kg}$.

The coefficient taking into account the drying days weather potentials is determined by formula (8):

$$
K_{i}=\left(\frac{i_{\mathrm{e} i}}{i_{\text {e.av }}}\right)^{0.75}
$$

where $i_{\text {eav }}$ - average long-term effective evaporation per day in the region where milled peat extraction is planned, $\mathrm{kg} / \mathrm{m}^{2}$;

$i_{\mathrm{e} i}$ - effective evaporation from the surface of soil evaporator per day, which corresponds to the evaporation discharge from the milled peat layer in determining the standard milling depth, $\mathrm{kg} / \mathrm{m}^{2}$.

According to the Moscow Peat Institute method, the water evaporation from the milled peat layer makes $2.4 \mathrm{~kg} / \mathrm{m}^{2}$ per day reasoning from the two-day cycle and the medium 
category of drying days, whereas in compliance with the All-Russian Research Institute of Peat Industry method, the average value of effective evaporation for days with the drying category D-2 is $i_{\text {e.av }}=\frac{3.41+5.20}{2}=4.30 \mathrm{~kg} / \mathrm{m}^{2}$.

The coefficient taking into account the decrease in drying rate as a result of uneven spread after milling (loosening) is determined by formula (9):

$$
K_{\mathrm{h}}=1+\mathrm{av} v_{\mathrm{h}}^{2}
$$

where a - empirical number; $v_{\mathrm{h}}$ - coefficient of variation of layer thickness after milling.

According to the All-Russian Research Institute of Peat Industry, prior to the peat deposit development, the coefficient of layer thickness variation can be set to 0.30 . In the process of exploitation of a peat deposit, the coefficient $v_{\mathrm{h}}$ must be determined experimentally. According to the research data of above-mentioned Institute, average empirical coefficient in formula (9) is a $=1.25$ (range from 1 to 1.5) [11].

In the technological scheme with a separate method of peat harvesting, milled peat is swathed into enlarged swaths by machines based on mechanical handling of crumb. Therefore, cycle harvesting for a two-day cycle duration is also calculated by formula (1). However, when determining the operational (initial) moisture content by formula (5), they do not take into account peat losses after harvesting since the production area under swaths is not milled during a season, and net is excluded from the calculation of area. Peat crumb losses after swathing are taken as $15 \%$.

In the technological scheme with a separate method of peat harvesting, a cycle harvesting factor increases due to significant reduction in crumb losses through multi-cycle harvesting of large cross section swaths, since the thickness of a layer remained after the harvester passage is approximately the same and does not depend on the peat swath size. Therefore, for a separate method of peat harvesting, the weighted average of cycle harvesting is determined by formula (10):

$$
q_{\mathrm{c} . \mathrm{av}}=\left(\mathrm{a}_{1} q_{\mathrm{c.d}}+\mathrm{a}_{2} q_{\mathrm{c} . \mathrm{dr}}\right) K_{i} K_{\mathrm{q}} / K_{\mathrm{h}}
$$

where $K_{\mathrm{q}}=1.1$ - coefficient taking into account the increase in cycle harvesting as a result of harvesting loss reduction.

In the technological scheme with a pneumatic method of peat harvesting, cycle harvesting is advisable to calculate according to the All-Russian Research Institute of Peat Industry methodology, i.e. by formulas (2 and 3). The coefficient of drying rate reduction due to uneven spread of milled peat is determined by formula (9). The cycle harvesting factors are set in accordance with a design thickness of the layer being dried in the range from 0.3 to 1.0 [12]. When one calculates the initial moisture content in the second and subsequent cycles after precipitation by formula (5), average moisture content over the whole layer is taken from Table. 1.

Table 1. Average moisture content over the whole layer when milled peat is harvested by pneumatic machines.

\begin{tabular}{|c|c|c|c|c|c|}
\hline $\begin{array}{c}\text { Moisture content of } \\
\text { the harvested peat, } \\
\text { kg / kg }\end{array}$ & \multicolumn{5}{|c|}{$\begin{array}{c}\text { Average moisture content (kg / kg), } \\
\text { given a harvesting factor }\end{array}$} \\
\cline { 2 - 6 } & $\mathbf{0 . 3}$ & $\mathbf{0 . 5}$ & $\mathbf{0 . 7}$ & $\mathbf{0 . 8}$ & $\mathbf{1 . 0}$ \\
\hline 1.2 & 1.88 & 1.68 & 1.48 & 1.38 & 1.2 \\
\hline 1.0 & 1.70 & 1.50 & 1.30 & 1.20 & 1.00 \\
\hline 0.8 & 1.47 & 1.29 & 1.09 & 0.99 & 0.80 \\
\hline
\end{tabular}




\begin{tabular}{|c|c|c|c|c|c|}
\hline 0.67 & 1.29 & 1.14 & 0.95 & 0.84 & 0.67 \\
\hline 0.5 & 1.05 & 0.91 & 0.78 & 0.64 & 0.50 \\
\hline 0.4 & 0.88 & 0.75 & 0.60 & 0.52 & 0.40 \\
\hline
\end{tabular}

The coefficient $\mathrm{M}$ in formula (3) can be calculated with fair accuracy by formula (11):

$$
\mathrm{M}=\mathrm{a}_{0}+\mathrm{a}_{1} W_{\text {in. }}
$$

where $\mathrm{a}_{0}$ и $\mathrm{a}_{1}$ are empirical coefficients (Table 2);

$W_{\text {in. }}$ - initial moisture content of milled peat, $\mathrm{kg} / \mathrm{kg}$.

Table 2. Empirical coefficients for calculating $M$ in relation to the pneumatic method of milled peat harvesting.

\begin{tabular}{|c|c|c|c|c|}
\hline \multirow{2}{*}{ Type of deposit } & \multirow{2}{*}{$\begin{array}{c}\text { Peat decay } \\
\text { degree, } \%\end{array}$} & \multicolumn{3}{|c|}{$\begin{array}{c}\text { Empirical coefficients ao/a1, given the number of } \\
\text { turnings per cycle }\end{array}$} \\
\cline { 3 - 5 } & & $\mathbf{1}$ & $\mathbf{2}$ & $\mathbf{3}$ \\
\hline Terrestrial peat & $10-45$ & $-1.61 / 1.45$ & $-1.08 / 1.18$ & $-0.75 / 1.02$ \\
\hline Lowland peat & $20-50$ & $-1.71 / 1.54$ & $-1.10 / 1.21$ & $-0.83 / 1.07$ \\
\hline Lowland peat & $<20$ & $-1.21 / 1.39$ & $-0.37 / 1.06$ & $-0.07 / 0.94$ \\
\hline
\end{tabular}

The initial moisture content $(\mathrm{kg} / \mathrm{kg})$ of the upper operational layer of a peat deposit for the third and subsequent years of exploitation is determined by formulas:

(a) Lowland peat deposit

$$
W_{\text {ex.d }}=\frac{82.9-0.195 \mathrm{R}}{100-(82.9-0.195 \mathrm{R})}
$$

b) Terrestrial peat deposit

$$
W_{\text {ex.d }}=\frac{83.0-0.135 \mathrm{R}}{100-(83.0-0.135 \mathrm{R})}
$$

where $\mathrm{R}$ - peat decay degree, $\%$.

For the first and the second years of peat deposit exploitation $t$, the initial moisture content calculated by formula (12) increases by $0.55(\mathrm{~kg} / \mathrm{kg})$.

With peat residues included, the initial moisture content makes

$$
W_{\text {ex.dr }}=\left(W_{\text {ex.d }}-W_{\text {hv }}\right) \alpha_{\mathrm{c}}+W_{\text {av }}
$$

The weighted average of cycle harvesting is determined by formula (14):

$$
q_{\mathrm{c} . \mathrm{av}}=0.2 q_{\mathrm{c} . \mathrm{d}}+0.8 q_{\mathrm{c} . \mathrm{d} r}
$$

where: 0.2 and 0.8 - the proportion of cycles in a post-precipitation season and when performing the second and subsequent cycles after precipitation;

$q_{\text {c.d }}, q_{\text {c.dr. }}$ - cycle harvesting of milled peat that makes allowance for operational normative moisture content of the peat deposit upper layer and for initial moisture content with due consideration of dried peat residues from the previous cycle, $t$ / ha. 


\section{Conclusions}

So, with regard to the mechanical method of harvesting, the performed calculations based on formulas $1-10$ allow us to state that the reduced to $15 \%$ cycle harvesting is possible to use in a design in comparison with that determined by the previous technical design standards. In respect to the calculation by formulas 11-14 for pneumatic peat harvesting with a one-day cycle duration, cycle harvesting makes $70-75 \%$ of the normative cycle harvesting with a two-day cycle duration.

\section{References}

1. A. Afanas'ev, Colloid Journal of the Russian Academy of Sciences: Kolloidnyi Zhurnal, $\mathbf{5 3 : 3 , ~} 425$ (1991)

2. O. Misnikov, Mires and Peat, 18, 1-15 (2016)

3. A. Afanas'ev, S. Gamayunov, O. Misnikov, Colloid Journal, 61:3, 274-279 (1999)

4. E. Kremcheev, D. Nagornov, Ecology, Environment and Conservation, 23:2, 956-965 (2017)

5. V. I. Smirnov, O. S. Misnikov, O. V. Pukhova, Mining Journal, 7, 67-71 (2014)

6. A. Afanas'ev, A. Boltushkin, Colloid Journal of the Russian Academy of Sciences: Kolloidnyi Zhurnal, 58:2, 139 (1996)

7. V. V. Panov, O. S. Misnikov, Mining Journal, 7, 108-112 (2015)

8. E. Kremcheev, D. Kremcheeva, Indian Journal of Science and Technology, 9:12, 89525 (2016)

9. B.F. Zyuzin, O.S. Misnikov, V.V. Panov, L.V. Kopenkina, Gornyi Zhurnal, 5, 73-76 (2013)

10. O. S. Misnikov, E. Yu. Chertkova, Eurasian Mining, 1:21, 63-68 (2014)

11. V. Lebedev, O. Puhova, E3S Web Conf., 21, 01023 (2017)

12. E. Chertkova, V. Sizova, E3S Web Conf., 105, 01015 (2019) 